Check for updates

Cite this: RSC Adv., 2018, 8, 3536

\title{
Effect of relative humidity on the gas transport properties of zeolite A/PTMSP mixed matrix membranes†
}

\author{
Ana Fernández-Barquín, (D) a Riccardo Rea, ${ }^{\mathrm{b}}$ Davide Venturi, ${ }^{\mathrm{b}}$ Marco Giacinti- \\ Baschetti, ${ }^{\mathrm{b}}$ Maria Grazia De Angelis, ${ }^{\mathrm{b}}$ Clara Casado-Coterillo (iD *a \\ and Ángel Irabien (iD) ${ }^{a}$
}

Increasing the knowledge of the influence of water vapor in new mixed matrix membranes (MMMs) could favor the integration of novel membrane materials in the recovery of $\mathrm{CO}_{2}$ from wet industrial streams. In this work, the water vapor effect on the $\mathrm{N}_{2}, \mathrm{CH}_{4}$ and $\mathrm{CO}_{2}$ permeability through MMMs comprised of 20 wt\% hydrophilic zeolite 4A in hydrophobic PTMSP polymer were investigated in the relative humidity range $0-75 \%$. While in the pure PTMSP membranes, the permeability of all gases decreases with water vapor activity, with almost unchanged $\mathrm{CO}_{2} / \mathrm{N}_{2}$ and $\mathrm{CO}_{2} / \mathrm{CH}_{4}$ selectivities, in zeolite A/PTMSP MMMs, the $\mathrm{CO}_{2}$ permeability increases with increasing water content in the system up to $50 \%$ R.H., resulting in an increase in $\mathrm{CO}_{2} / \mathrm{N}_{2}$ and $\mathrm{CO}_{2} / \mathrm{CH}_{4}$ selectivities with respect to pure PTMSP. Gas sorption was studied so that the effect the residual humidity in the zeolite $4 \mathrm{~A}$ has on the sorption of the different gases helped explaining the permeability observations. The sorption and humid permeation behavior were evaluated by a simple model equation based on the NELF theory, taking into account the multicomponent gas sorption and diffusion in the presence of humidity, as well as the counteracting effects of the hydrophobic PTMSP and hydrophilic zeolite A in a very accurate way.

Received 4th December 2017 Accepted 10th January 2018

DOI: 10.1039/c7ra13039b

rsc.li/rsc-advances
Polymeric membranes show the highest maturity among the existing membrane materials for $\mathrm{CO}_{2}$ separation, although relatively few polymeric membranes have been commercialized for gas separation, compared to the number of polymeric materials commercially available. ${ }^{8}$ This is attributed to various reasons such as the lack of performance on productivity and separation selectivity, as polymeric membranes normally present a trade-off between selectivity and permeability, ${ }^{9}$ as well as module fabrication and lack of information regarding the performance in the presence of impurities in the $\mathrm{CO}_{2}$ streams, such as water vapour. ${ }^{10}$

Mixed matrix membranes (MMMs) constitute one of the ways of enhancing the performance of polymeric membranes. MMM combine the molecular sieving effect of inorganic fillers with the good processability of polymers achieving new materials with synergistic functional properties. ${ }^{\mathbf{1 1}}$ Material selection for both polymeric matrices and sieve phases is a key aspect in the synthesis of MMMs. As the performance of the MMM is limited by the polymer performance, a highly performing polymer should be used as continuous matrix. ${ }^{12,13}$ In this work, poly(1-trimethylsilyl-1-propyne) (PTMSP), a polymer with one of the highest gas permeabilities, was chosen. PTMSP is a glassy polymer with extremely high fractional free volume $(0.29){ }^{\mathbf{1 4 , 1 5}}$ whose glassy structure leads to a low chain mobility and a glass transition temperature higher than $523 \mathrm{~K}$, making it a good material for high temperature gas separations. ${ }^{16,17}$ However, its large gas permeability is coupled with low ideal selectivity ${ }^{9}$ and 
a tendency to undergo physical ageing, ${ }^{18}$ which limits the applicability of PTMSP as pure membrane material. We have overcome these drawbacks by adding small-pore zeolites with low Si/Al ratio to the hydrophobic PTMSP polymer, and both components showed good compatibility so that no defects were found in the interphase between the polymer and the filler. ${ }^{19}$

The effect of minor compounds frequently present in industrial separations can affect significantly the polymer membrane behaviour. ${ }^{20,21}$ In particular, the influence of water vapour on membrane permeability and selectivity is stronger than that of other minor components regarding competitive sorption, plasticization and ageing. ${ }^{2}$ Besides, this influence depends on the hydrophilic or hydrophobic character of the membrane material or the affinity of water with the different gases. $^{22,23}$ In spite of the amount of works on high free volume glassy membranes, ${ }^{\mathbf{1 6 , 2 4 , 2 5}}$ to the best of our knowledge, only a few have dealt with the water effect on the gas permeability through such polymer membranes as PTMSP, PIM-1 and thermally rearranged (TR) materials. ${ }^{21,26,27}$ In all such membranes, the presence of humidity reduced the gas permeability affecting to a lesser extent the selectivity. Therefore, there is still limited information on the effect of water vapour in these high free volume polymer membranes, ${ }^{\mathbf{1 7}, 28}$ and even less in MMMs.

In this work, we studied the water vapour effect on $\mathrm{N}_{2}, \mathrm{CH}_{4}$ and $\mathrm{CO}_{2}$ gas sorption and permeation through the $20 \mathrm{wt} \%$ zeolite $\mathrm{A} /$ PTMSP MMM developed in our laboratory ${ }^{19}$ in the range $0-75 \%$ relative humidity (R.H.). This MMM is comprised of a hydrophilic porous filler in a hydrophobic high free volume matrix. The performance of the MMM has been compared to that of pure PTMSP membranes. These experimental results have been described by a simple but effective model that describes the permeation process under humid conditions in the framework of the solution-diffusion mechanism. In particular, the free volume theory was considered to account for the gas diffusivity ${ }^{29}$ while the solubility, taking into account the multicomponent competitive sorption of gas and water in the membrane, ${ }^{30}$ was modelled by the NELF model. For this purpose, the $\mathrm{N}_{2}, \mathrm{CH}_{4}$ and $\mathrm{CO}_{2}$ sorption curves of this MMM have been also experimentally obtained by means of the pressure-decay technique to be introduced in the model applied in this work.

\section{Results and discussion}

In Fig. 1, the $\mathrm{N}_{2}, \mathrm{CH}_{4}$ and $\mathrm{CO}_{2}$ permeabilities obtained at $35{ }^{\circ} \mathrm{C}$ and 1 bar of upstream pressure, in the range of $0-75 \%$ R.H. are plotted as a function of water vapour activity. The dry gas permeability of pure PTMSP membranes agrees with the range reported for other PTMSP membranes in literature. ${ }^{\mathbf{1 6 , 2 4 , 2 5}}$

Interestingly, the addition of zeolite A to PTMSP in the MMM caused a decrease of permeability in the order of magnitude of $50 \%$ for $\mathrm{N}_{2}$ and $\mathrm{CH}_{4}$, and to a lesser extent for $\mathrm{CO}_{2}$. This has been previously attributed to the MMM dual-layer morphology, as already reported in a previous work. ${ }^{19}$ This MMM is comprised of two layers, one almost pure PTMSP layer at the top, and a zeolite layer at the bottom where the PTMSP acts as binder and the zeolite particles partly occupy the free volume of the final MMM. This contributes to the rigidification and

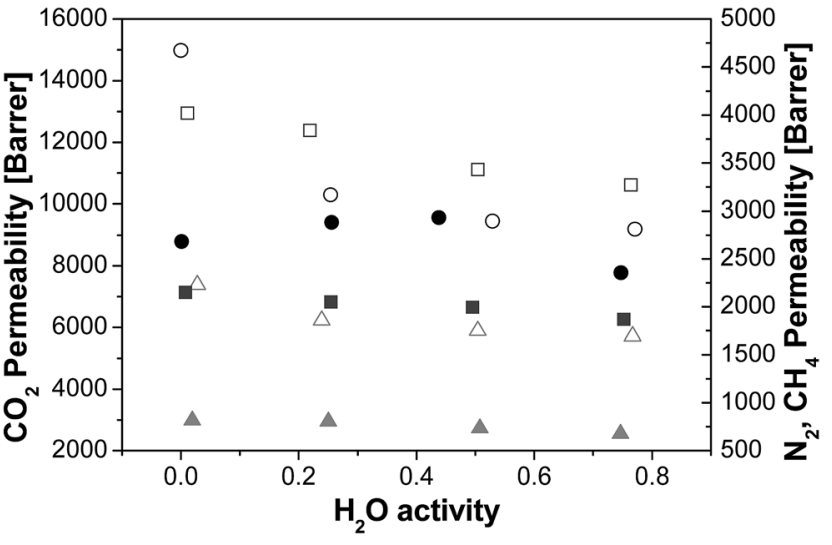

Fig. 1 Permeability (barrer) at different relative humidity $\left(T=35^{\circ} \mathrm{C} p=\right.$ 1 bar) for the zeolite A/PTMSP MMM (full symbols) and PTMSP membranes (void symbols). $\mathrm{N}_{2}$ (grey triangles), $\mathrm{CH}_{4}$ (dark grey squares) and $\mathrm{CO}_{2}$ (black circles).

densification of the membrane matrix, by reducing further the flexibility of the polymer chains and somewhat inhibiting the gas diffusion. ${ }^{31}$ In that work, we observed that the $\mathrm{CO}_{2}$ permeability decreased with increasing temperature up to a maximum zeolite loading that depended on the composition of the zeolite particles, thus revealing the molecular sieving effect of the zeolite A in the PTMSP matrix.

Regarding the water effect, the gas permeability through PTMSP membranes generally decreased with increasing water activity for all gases investigated, in agreement with other polyimide membranes made of PIM-1 ${ }^{21,32}$ or Matrimid, ${ }^{29}$ due to the reduction in diffusivity when water molecules occupy part of the free volume of the polymer. The gas permeability through the zeolite A/PTMSP MMM also decreased for $\mathrm{N}_{2}$ and $\mathrm{CH}_{4}$ with increasing water activity, while the $\mathrm{CO}_{2}$ permeability showed a slight increase to about $50 \% \mathrm{RH}$, followed by a slight decrease. At average relative humidity, the $\mathrm{CO}_{2}$ permeability of the MMM is similar to the value measured in pure PTMSP membranes. The behaviour of the humid gas permeability in zeolite A/PTMSP MMM can be correlated qualitatively with the gas sorption in the pure zeolite A particles, at two different hydration levels. It is well known that zeolite A is extremely hydrophilic, so that it contains some water adsorbed from the environment, at ambient conditions. ${ }^{33,34}$ Such water can be removed by treating the system at high temperatures. The exact quantification of the amount of water adsorbed by the zeolite as a function of relative humidity and temperature was beyond the scope of the present paper, although we checked by thermal gravimetric analysis (shown in Fig. S1 of the ESI $\dagger$ ), the water content in the undried and dried zeolite, obtaining a $12.6 \%$ and $5.7 \%$ content of water in the undried, "as received", and dried at $105{ }^{\circ} \mathrm{C}$ zeolite, respectively, to account for the effect of the residual water content in the zeolite sample on the sorption of the different gases with different contents of humidity (Fig. S2 of the ESI $\dagger$ ). Since the residual water content in the MMM is in the range 0.5 to $3.1 \mathrm{wt} \%$, with increasing zeolite A loading, which accounts for the dispersion of the hydrophilic zeolite in the hydrophobic polymer matrix, 
these data can help interpreting the humid permeability results.

On one hand, from Fig. S2a, $\uparrow$ it seems that the $\mathrm{CO}_{2}$ adsorption in the zeolite is not inhibited by the presence of water, possibly due to the higher affinity of $\mathrm{CO}_{2}$ for water molecules. ${ }^{29,35}$ On the other hand, we can see in Fig. S2b and S2c $\dagger$ that the uptake of $\mathrm{CH}_{4}$ and $\mathrm{N}_{2}$ in the dried zeolite sample is much higher than that measured on the undried one, which contains water molecules adsorbed from the atmosphere. This means that the water present in zeolite A does inhibit the sorption of gases like $\mathrm{CH}_{4}$ and $\mathrm{N}_{2}$ due to competitive effects. This behaviour is consistent with that observed in the humid permeability of the zeolite A/PTMSP MMM, where the relative humidity was detrimental for the permeation of $\mathrm{N}_{2}$ and $\mathrm{CH}_{4}$, but not for the transport of $\mathrm{CO}_{2}$ molecules. Besides, the shape of the isotherms is similar to those obtained for the zeolite A at the same conditions of this work, i.e. low pressures, by Palomino et al. ${ }^{36}$

The effect of water on permeability is clarified using the normalized gas permeability, defined as the ratio between the permeability at a given R.H. and the dry gas permeability, and plotted on Fig. 2. Indeed, the normalised gas permeability of pure PTMSP membranes shows a similar decrease for all three gases with increasing water activity, being somewhat stronger for $\mathrm{CO}_{2}$. In particular, the $\mathrm{CO}_{2}$ permeability through the PTMSP membranes is decreased by $40 \%$ from the dry value at a water activity of 0.75 , whereas the permeability of $\mathrm{N}_{2}$ and $\mathrm{CH}_{4}$ is only reduced by $20 \%$. The data agree with the reduction of $\mathrm{N}_{2}$ permeability reported by Scholes et al. ${ }^{21}$ in mixed gas separation experiments and water activity below 0.40 . The reduction in $\mathrm{CO}_{2}$ permeability reported by those authors was lower than $12 \%$, thus smaller than the reduction observed here.

The large decrease of the $\mathrm{CO}_{2}$ permeability through the PTMSP membrane is related to a combination of competitive sorption of $\mathrm{N}_{2}$ and $\mathrm{CH}_{4}$ with water in the micro cavities, ${ }^{32}$ water clustering and pore blockage, which reduce diffusivity and $\mathrm{CO}_{2}$ solubility, thus compensating the effect of $\mathrm{CO}_{2}$ dissolution in water and the expected increase in $\mathrm{CO}_{2}$ permeation through the membrane. ${ }^{37}$ The permeability reduction with increasing water activity will be evaluated in the next section when discussing the modelling. ${ }^{38}$

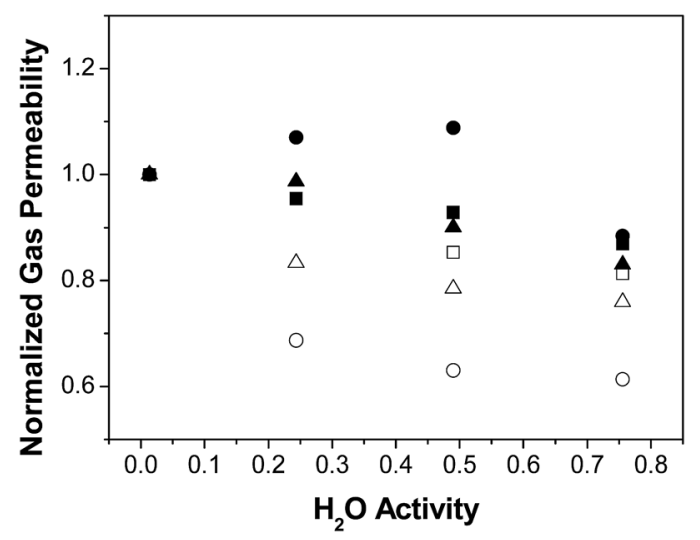

Fig. 2 Normalised gas permeability $P / P_{\text {dry }}$ through the zeolite $A /$ PTMSP MMM, (full symbols) PTMSP membranes (void symbols): $\mathrm{N}_{2}$ (triangles), $\mathrm{CH}_{4}$ (squares), $\mathrm{CO}_{2}$ (circles).
Such decreasing trend in permeability was also observed for $\mathrm{N}_{2}$ and $\mathrm{CH}_{4}$ through the zeolite A/PTMSP MMM, though less pronounced than that of pure PTMSP membranes.

The deviations are attributed to the different experimental set-ups. The influence of water activity on gas permeability visible in Fig. 2 was definitively lower in the case of the zeolite A/ PTMSP MMM than in the pristine PTMSP membrane. On average, the gas permeability of the MMM decreased by $9 \%$ and $15 \%$ from the dry permeability at 0.5 and 0.75 water activity, respectively. The decrease in gas permeability never exceeded 15 $\pm 2.6 \%$ in the R. H. range investigated. The error of experimental permeabilities, calculated by experiments repetition, is always below $3 \%$. In contrast, the $\mathrm{CO}_{2}$ permeability increases up to $10 \%$ at a water activity of 0.50 , due to the higher affinity of $\mathrm{CO}_{2}$ with water, ${ }^{29}$ the hydrophilic character of zeolite $\mathrm{A}^{33,34}$ and the higher sorption at higher water activities. ${ }^{39}$ The reduction of $\mathrm{CO}_{2}$ permeability through MMM observed in Fig. 2 may be attributed to the combination of competitive sorption between

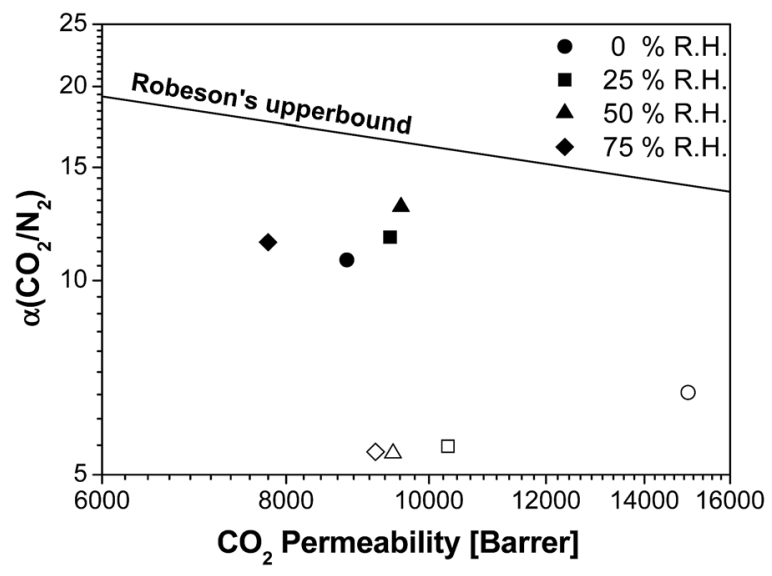

(a)

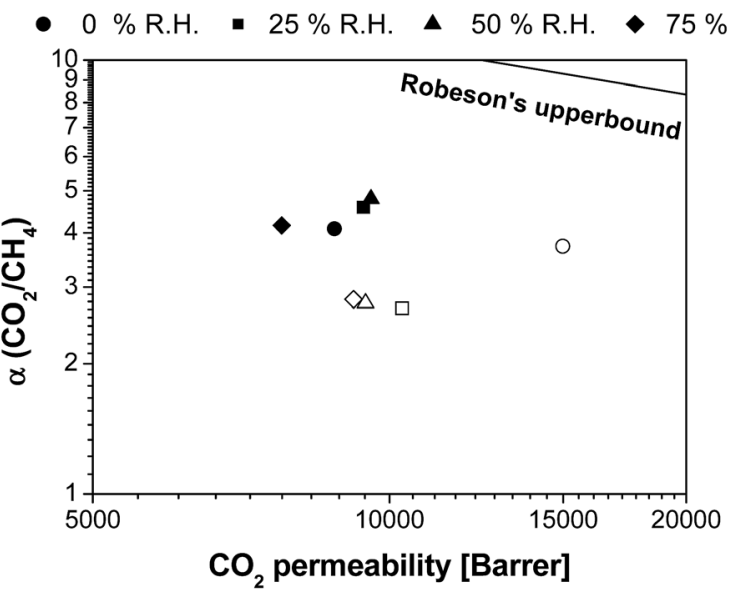

(b)

Fig. 3 Comparison of (a) $\mathrm{CO}_{2} / \mathrm{N}_{2}$ and (b) $\mathrm{CO}_{2} / \mathrm{CH}_{4}$ selectivity as a function of R.H. with the Robeson's upper bound. ${ }^{9}$ Open symbols: PTMSP. Filled symbols: zeolite A/PTMSP MMM. The symbols indicate the direction towards increasing relative humidity values as follows: $0 \%$ (circles) $<25 \%$ (squares) $<50 \%$ (triangles) $<75 \%$ (rhombuses). 
water and gas molecules and the plasticization by water of the high free volume polymer, as observed also by Nakamura et al. ${ }^{28}$ for PTMSP-related membranes in dry and wet states.

Fig. 3 shows the effect of the R.H. on the membrane separation performance in terms of the distance from the Robeson upper bound. ${ }^{9}$ In general, the $\mathrm{CO}_{2} / \mathrm{N}_{2}$ and $\mathrm{CO}_{2} / \mathrm{CH}_{4}$ selectivities of pure PTMSP are not strongly affected by the presence of water in the feed, with a slight increment in the distance from the upper bound upon increasing R.H., as observed in Matrimid. ${ }^{29}$ In contrast, it is clear that the overall permselectivity of the zeolite A/ PTMSP MMM approaches the upper bound with increasing R.H., up to $50 \%$. The difference in membrane performance in the presence of water vapour is attributed to the presence of the zeolite, which increased the membrane selectivity in humid conditions. This is due to the enhancement in the $\mathrm{CO}_{2}$ permeability of the MMM with the water content in the gas feed, which leads to an additional improvement in the $\mathrm{CO}_{2}$ selectivity in the presence of water, with respect to dry conditions.

The $\mathrm{CO}_{2}$ permeability of the MMM is slightly lower than that of the pristine PTMSP membrane and the increase in $\mathrm{CO}_{2} / \mathrm{CH}_{4}$ selectivity is not high enough to counteract the decrease in $\mathrm{CO}_{2}$ permeability, thus the separation performance is maintained at about the same distance from the upper bound. This agrees with other MMM formed by zeolites and glassy polymers, because of the combined effects of $\mathrm{CH}_{4}$ and water vapour on $\mathrm{CO}_{2}$ permeation. ${ }^{37}$ This is also attributed to the reduction of free volume by the space occupied by the zeolite particles and the rigidity imparted to the polymer matrix thereby, ${ }^{19}$ which has a larger effect than plasticization or competitive sorption. ${ }^{40}$ This issue requires some research effort in the materials knowledge, but as a starting point it can be noticed that the $\mathrm{CO}_{2}$ solubility of the hydrated zeolite is almost the same as the dried zeolite, in opposition to the solubility of $\mathrm{N}_{2}$ or $\mathrm{CH}_{4}$, as discussed above regarding Fig. S2.†

\subsection{Modelling of permeability in the presence of water}

2.1.1. Modelling the gas solubility in the membranes. First of all, the competitive sorption effects between the gases and water in the membrane were studied in the MMM and PTMSP membranes using a thermodynamic model that describes the solubility of gases and vapours in glassy polymers, i.e. the NonEquilibrium Thermodynamic model for glassy polymers. ${ }^{\mathbf{4 1 , 4 2}}$ This model describes the non-equilibrium behaviour of a glassy polymer by using the actual polymer density as additional state variable, in order to account for the departure from equilibrium conditions. The NET-GP approach is applied by using the lattice fluid model by Sanchez-Lacombe, ${ }^{43}$ giving rise to the so-called Non-Equilibrium Lattice Fluid (NELF) model. The main characteristic parameters necessary in this work are collected in Table 1. The model parameters to describe the gas solubility by NELF are a binary gas molecule-membrane interaction parameter, $k_{\mathrm{ij}}$, involving the characteristic pressure of the gas-polymer mixture, and a swelling coefficient, $k_{\mathrm{sw}}$, defined as the ratio between the relative polymer volume increase and the gas pressure. ${ }^{30}$ They are estimated for PTMSP by adjusting the NELF model ${ }^{44}$ with the experimental $\mathrm{N}_{2}, \mathrm{CH}_{4}$ and $\mathrm{CO}_{2}$ sorption isotherms obtained
Table 1 Sanchez Lacombe EoS characteristic parameters for PTMSP 46 and gas and vapor molecules ${ }^{42}$

\begin{tabular}{llll}
\hline Component & $T^{*}(\mathrm{~K})$ & $p^{*}(\mathrm{MPa})$ & $\rho^{*}\left(\mathrm{~g} \mathrm{~cm}^{-3}\right)$ \\
\hline PTMSP & 416 & 405 & 1.250 \\
$\mathrm{CO}_{2}$ & 300 & 630 & 1.515 \\
$\mathrm{~N}_{2}$ & 145 & 160 & 0.943 \\
$\mathrm{CH}_{4}$ & 215 & 250 & 0.500 \\
$\mathrm{H}_{2} \mathrm{O}$ & 670 & 2400 & 1.050
\end{tabular}

experimentally for the PTMSP membranes, which agree with previously reported literature, ${ }^{\mathbf{4 0 , 4 5}}$ as shown in Fig. 4, using the characteristic parameters of Table 1 .

The $k_{\mathrm{ij}}$, gas-polymer interaction parameter and $k_{\mathrm{sw}}$, swelling parameter calculated for PTMSP are reported in Table 2. Such parameters were adjusted with the pure gas solubility isotherms in pristine PTMSP membranes, as represented in Fig. S3 in the ESI. $\dagger$ For all gases, $k_{\mathrm{ij}}$ is slightly positive, in agreement with the values reported for other glassy polymers as PIM-1 ${ }^{47}$ and HAB6FDA polyimides. ${ }^{48}$ For water vapour sorption, the binary parameters reported in Table 2 were adjusted using the isotherm reported by Scholes et al. ${ }^{21}$

In addition, the model has been modified to take into account the gas sorption into MMMs. ${ }^{\mathbf{4 6 9}}$ The mass of penetrant adsorbed in the MMM per unit mass of total solid, $\Omega_{\mathrm{M}}$, is evaluated from the mass adsorbed on the pure filler per unit mass of filler, $\Omega_{\mathrm{F}}$, and that adsorbed in the polymeric phase of the MMM per unit mass of polymer, $\Omega_{\mathrm{P}, \mathrm{MM}}$ :

$$
\Omega_{\mathrm{M}}=w_{\mathrm{F}} \times \Omega_{\mathrm{F}}+\left(1-w_{\mathrm{F}}\right) \times \Omega_{\mathrm{P}, \mathrm{MM}}
$$

For "ideal" MMMs, the sorption capacities of the polymer and the filler in the composite material are considered equal to the pure component values so a simple additive rule is used to determine the sorption capacity of the composite. However, mixed matrices of high free volume glassy polymers, such as PTMSP, may not show this additive behaviour because of how the inorganic rigid phase affects the volumetric space of the polymer. ${ }^{50}$ In a first approximation, however, we can assume that the adsorption capacity of the filler remains the same as in pure state:

$$
\Omega_{\mathrm{F}}=\Omega_{\mathrm{F}}^{0}
$$

Eqn (2) becomes:

$$
\Omega_{\mathrm{M}}=w_{\mathrm{F}} \Omega_{\mathrm{F}}^{0}+\left(1-w_{\mathrm{F}}\right) \times \Omega_{\mathrm{P}, \mathrm{MM}}
$$

where, in general, polymer properties in the mixed matrix are different from the corresponding pure component values:

$$
\Omega_{\mathrm{P}, \mathrm{MM}} \neq \Omega_{\mathrm{P}}^{0}, \rho_{\mathrm{P}, \mathrm{MM}} \neq \rho_{\mathrm{P}}^{0} \text { and } \mathrm{FFV}_{\mathrm{P}, \mathrm{MM}} \neq \mathrm{FFV}_{\mathrm{P}}^{0}
$$

By applying the NELF model, ${ }^{41-44}$ the value of $\Omega_{\mathrm{P}, \mathrm{MM}}$ is univocally related to the $\mathrm{MM}$ polymer density $\rho_{\mathrm{P}, \mathrm{MM}}$ :

$$
\Omega_{\mathrm{P}, \mathrm{MM}}^{\mathrm{NELF}}=f\left(T, p, \rho_{\mathrm{P}, \mathrm{MM}}\right)
$$




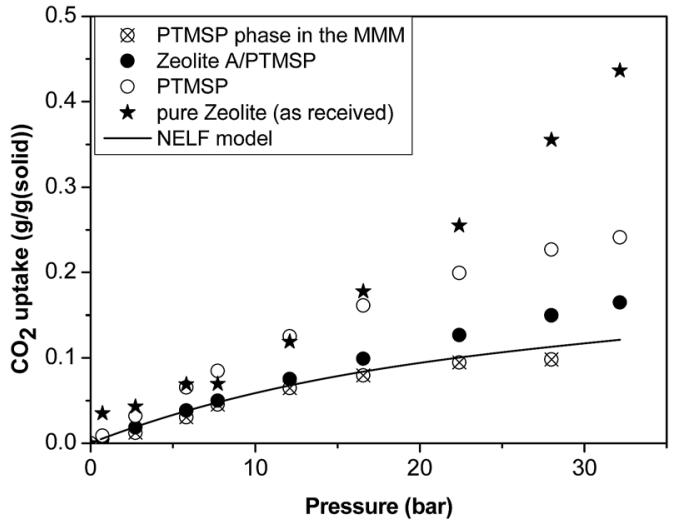

(a)

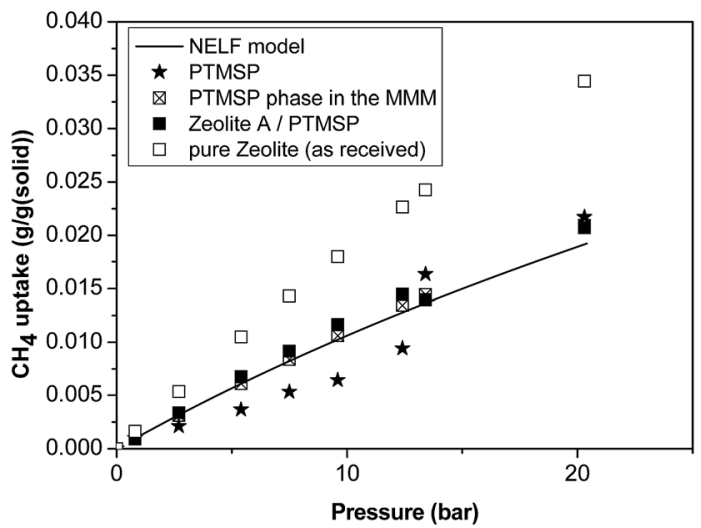

(b)

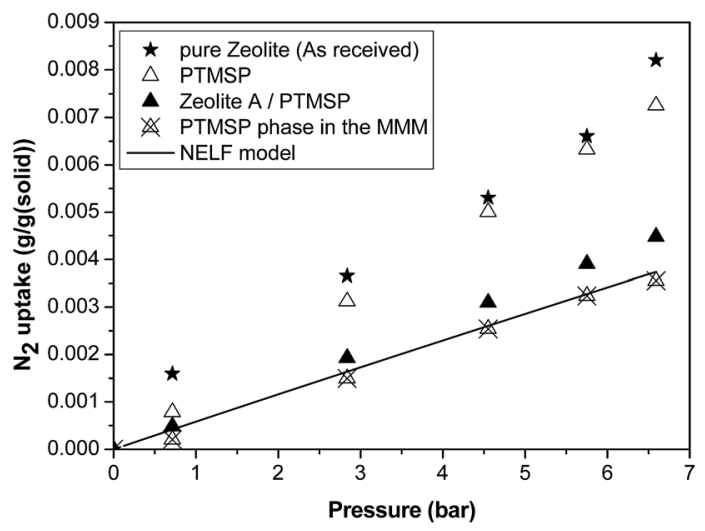

(c)

Fig. 4 Sorption isotherms in the pure zeolite, pure PTMSP, zeolite A/ PTMSP MMM and the PTMSP phase in the MMM. The solid line represents the adjustment with the NELF model.

Eqn (4) was used to estimate the density of the polymer phase in the MMM, $\rho_{\mathrm{P}, \mathrm{MM}}$. This density value can be associated to the fractional free volume value in the $\mathrm{MMM}_{\mathrm{N}} \mathrm{FFV}_{\mathrm{P}, \mathrm{MM}}$ by

$$
\mathrm{FFV}_{\mathrm{P}, \mathrm{MM}}=\frac{\rho_{\mathrm{P}}^{\mathrm{vdW}}-1.3 \rho_{\mathrm{P}, \mathrm{MM}}}{\rho_{\mathrm{P}}^{\mathrm{vdW}}}
$$

Table 2 Binary gas-PTMSP interaction and swelling parameters for the NELF model for the PTMSP sorption isotherms in Fig. S3 in ESI

\begin{tabular}{lll}
\hline & \multicolumn{2}{l}{ PTMSP } \\
\cline { 2 - 3 } Components & $k_{\mathrm{ij}}$ & $k_{\mathrm{sw}}\left(\mathrm{MPa}^{-1}\right)$ \\
\hline $\mathrm{CO}_{2}$ & 0.075 & 0.009 \\
$\mathrm{CH}_{4}$ & 0.020 & 0.007 \\
$\mathrm{~N}_{2}$ & 0.10 & 0 \\
$\mathrm{H}_{2} \mathrm{O}$ & -0.17 & 0 \\
\hline
\end{tabular}

Thus, the sorption isotherm in the polymeric phase of the MMM, $\Omega_{\mathrm{P}, \mathrm{MM}}$, was adjusted by NELF model and eqn (4), looking at the MMM, pure zeolite and PTMSP membrane sorption data, and allowing $\rho_{\mathrm{P}, \mathrm{MM}}$ and $k_{\mathrm{sw}}$ to iterate, while keeping $k_{\mathrm{ij}}$ equal to the value obtained for pure PTMSP (Table 2). The sorption isotherms thus obtained are represented in Fig. 4 for $\mathrm{CO}_{2}, \mathrm{CH}_{4}$ and $\mathrm{N}_{2}$, respectively. Here, it is observed that the polymer phase in the MMM adsorbs less gas than in the pure state. This is attributed to the fact that the polymeric matrix is constrained by the presence of the zeolite.

The density of the polymer in the MMM can be lower or higher than the pure polymer density in the same operation conditions, depending on the interaction with the filler. For instance, the polymer density decreased, resulting in lower FFV and transport parameters in MMM where silica domains were generated in situ in a PTMSP solution via sol-gel. ${ }^{51}$ Other studies $^{31,52}$ revealed that when pre-formed hydrophobic fumed non-porous silica particles were added to PTMSP, lower density of the MMM than the pure PTMSP membranes was achieved, resulting in additional free volume mainly due to poor adhesion. The porous zeolite particles are larger than those non-porous silica particles so they are not supposed to disrupt the chain packing and the changes in density and permeability are caused by the flow through the zeolite particles, which depends on the size and morphology, influencing the compatibility with the polymer matrix. ${ }^{53}$ In particular, the value of $\rho_{\mathrm{P}, \mathrm{MM}}$ that best adjusts the data of all the gases is equal to $0.885 \mathrm{~g} \mathrm{~cm}^{-3}$, which is higher than the value for pure PTMSP membranes, and corresponds to a lower fractional free volume $\mathrm{FFV}_{\mathrm{P}, \mathrm{MM}}$ of 0.162 . The swelling coefficient $k_{\mathrm{sw}}$ diminishes from 0.007 to $0.005 \mathrm{MPa}^{-1}$, for $\mathrm{CH}_{4}$, and from $0.005 \mathrm{MPa}^{-1}$ to zero for $\mathrm{CO}_{2}$. This indicates a rigidification of the polymer matrix in the MMM.

2.1.2. Modelling of the humid gas permeability. The effect of water activity, $a$, in the membrane on the gas permeability can thus account for the effects on gas solubility, due to competitive sorption, and gas diffusivity, due to the free volume reduction, on the permeability, according to the solutiondiffusion mechanism, ${ }^{30}$ as

$$
P(a)=D(a) S(a)=A \exp \left(\frac{-B}{\operatorname{FFV}(a)}\right) S(a)
$$

where $A$ and $B$ are the parameters that correlate the model with the membrane material properties, for each penetrant gas. ${ }^{43,54}$ 
Table 3 Parameters considered for the diffusivity and diffusivity + solubility based modelled permeability

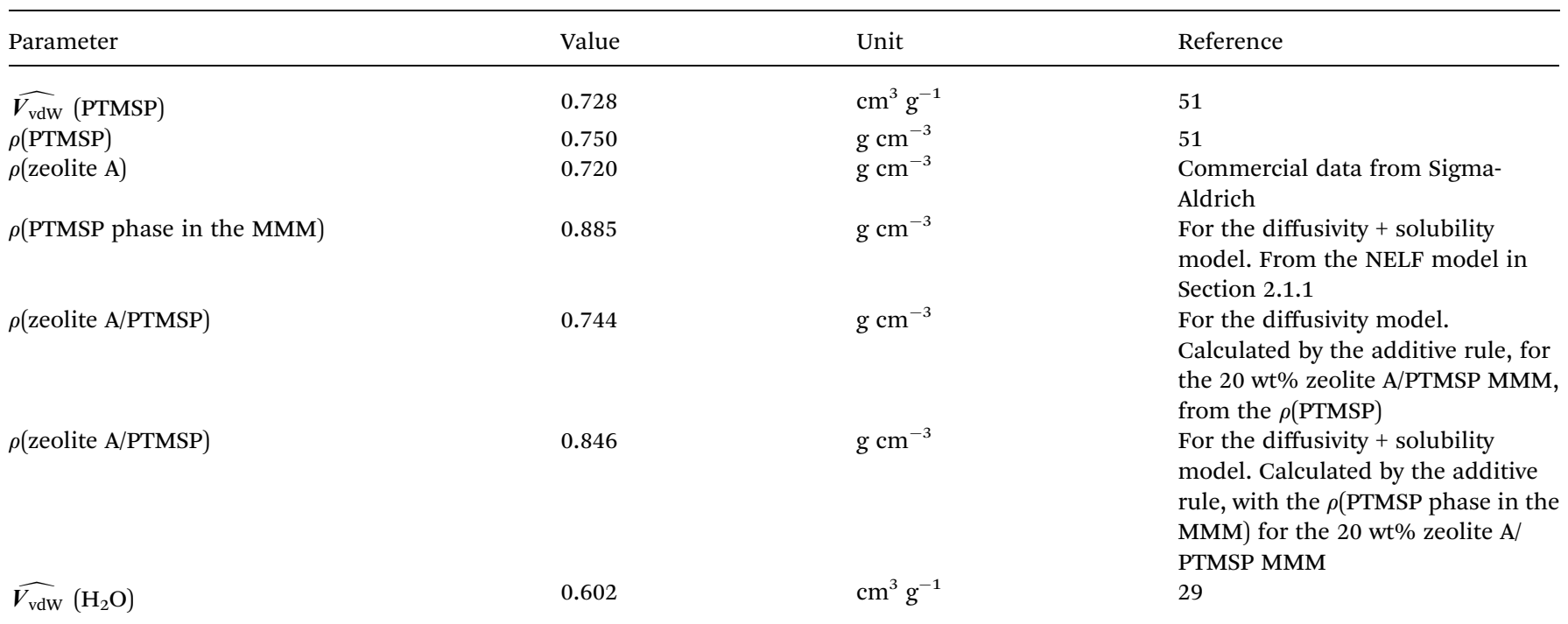

Since for rigid glassy polymers the diffusivity is known to dominate the transport of small substances ${ }^{55}$ in this work, two approaches have been undertaken to model the influence of water activity on permeability. The first one considers that the predominant effect of water in the membrane matrix is due to the kinetic part of permeability in eqn (6), that is, the diffusivity. The humid gas permeability is thus expressed in terms of the humid fractional free volume, FFV, as function of the water activity $a$, with two adjustable parameters that depend on the gas penetrant $i,{ }^{29,56}$ using a simple but effective model reported recently by Ansaloni et al., ${ }^{20}$ as

$$
P(a)=D(a)=A_{i} \exp \left(\frac{-B_{i}}{\operatorname{FFV}(a)}\right)
$$

This approach estimates that the permeability reduction observed in the PTMSP-based membranes in the presence of water is only due to the reduction of the free volume because of the partial occupation by the absorbed water molecules and the zeolite particles embedded in the polymer matrix. No swelling is induced by the water vapour, due to the high rigidity of the membrane matrix and the low quantity of absorbed water by the polymer. ${ }^{21}$ When water is present, the FFV is estimated by considering both the occupied volume of the polymer chains, the zeolite particles and the water molecules adsorbed in the membrane matrix. ${ }^{57,58}$ The volume of a water molecule is assumed to be constant and proportional to its van der Waals volume over the whole water activity range. The expression that links the FFV with the water activity in this approach is given by eqn (8),

$$
\operatorname{FFV}(a)=1-1.3 \frac{\widehat{V_{\mathrm{vdW}}}}{\hat{V}}-1.3 \frac{\widehat{V_{\mathrm{vdW}, \mathrm{H}_{2} \mathrm{O}}}}{\hat{V}} \Omega(a)
$$

where $\hat{V}$ and $\widehat{V_{\mathrm{H}_{2} \mathrm{O}}}$ are the occupied volumes of the membrane and water, $\widehat{V_{\mathrm{vdW}}}$ and $\widehat{{\mathrm{VdW}, \mathrm{H}_{2} \mathrm{O}}_{\mathrm{O}}}$ are the membrane and water van der Waals volume, respectively, estimated by Bondi's method. ${ }^{59}$
$\Omega(a)$ is the amount of water vapour in the membrane, expressed as $\mathrm{g}_{2} \mathrm{O} / \mathrm{g}$ membrane. In this work, this value for the pristine PTMSP membrane has been taken from water solubility isotherms reported in literature, ${ }^{21}$ while that of the zeolite A/ PTMSP MMM has been calculated by the additive rule from water sorption in PTMSP and zeolite $\mathrm{A},{ }^{60}$ respectively. All the parameters used to calculate the FFV in eqn (8) are given in Table 3.

When calculating the effect of water on the gas solubility, $S(a)$, the multicomponent sorption has to be considered. Thus, a gas-water interaction parameter $k_{\mathrm{ij}}$ (Table 4 ), was added to the NELF characteristic parameters in Table 1 and the gas-polymer interaction and swelling parameters in PTMSP and MMM, $k_{\mathrm{ij}}$ and $k_{\mathrm{sw}}$, calculated above, in order to model the solubility of $\mathrm{CO}_{2}, \mathrm{CH}_{4}$ and $\mathrm{N}_{2}$ in zeolite A/PTMSP MMM and pristine PTMSP membranes, in the presence of relative humidity.

The calculated humid gas solubilities $S(a)$ are plotted in Fig. 5 as a function of the water activity. It is worth remarking that the solubility of $\mathrm{CO}_{2}$ increases with increasing water content while the solubility of the other gases decreases, because of their general lower solubility. ${ }^{30}$ These observations explain some of the experimental observations discussed above, by the affinity of $\mathrm{CO}_{2}$-water, and the $k_{\mathrm{ij}}$ in Table 4 .

The effect of water activity in diffusivity has been estimated using the experimental data of humid gas permeability and the humid gas solubility of the membranes obtained by NELF model shown in Fig. 5, by means of the solution diffusion

Table 4 Gas-water interaction parameters used in this work, from VLE and solubility data from ${ }^{30,61}$

\begin{tabular}{ll} 
Components & $k_{\mathrm{ij}}$ \\
\hline $\mathrm{CO}_{2}-\mathrm{H}_{2} \mathrm{O}$ & -0.117 \\
$\mathrm{CH}_{4}-\mathrm{H}_{2} \mathrm{O}$ & 0 \\
$\mathrm{~N}_{2}-\mathrm{H}_{2} \mathrm{O}$ & 0
\end{tabular}




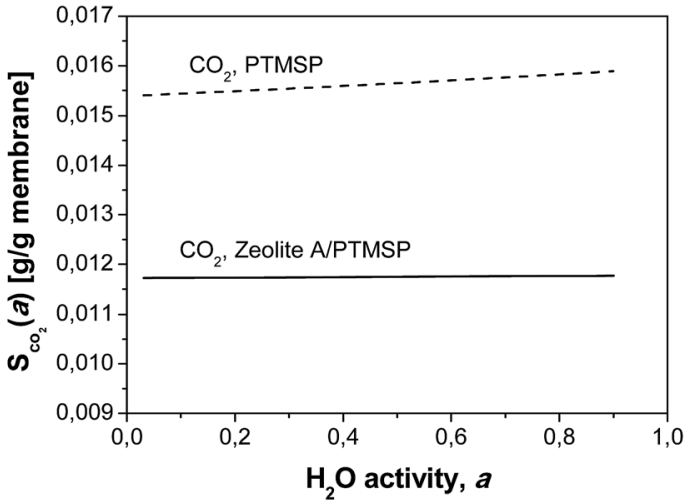

(a)

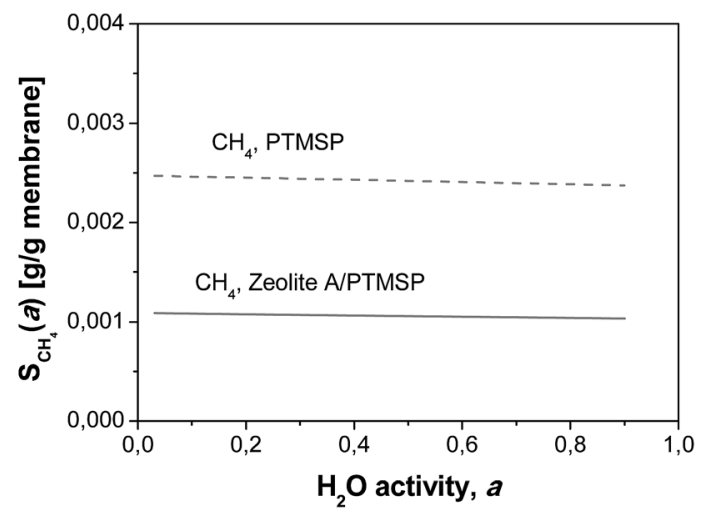

(b)

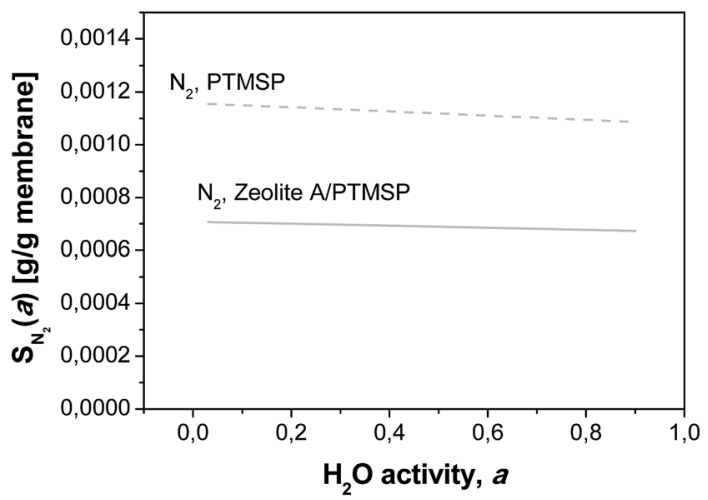

(c)

Fig. 5 Calculated humid gas solubility $S(a)$ as a function of water activity of (a) $\mathrm{CO}_{2}$, (b) $\mathrm{CH}_{4}$ and (c) $\mathrm{N}_{2}$, and in the PTMSP membrane (dotted lines) and the zeolite A/PTMSP MMM (continuous lines) calculated by the NELF model, at the same pressure and temperature as the experimental isotherms.

model. The humid gas diffusivities calculated this way are represented in Fig. 6. It can be seen that the expected strong influence of the decrease in gas diffusivity in the permeability with increasing water activity through the pristine PTMSP membranes is somehow softened by the effect of the zeolite particles in the MMM, because of the combining effects of competitive gas sorption and water clustering and membrane matrix rigidification mentioned above.

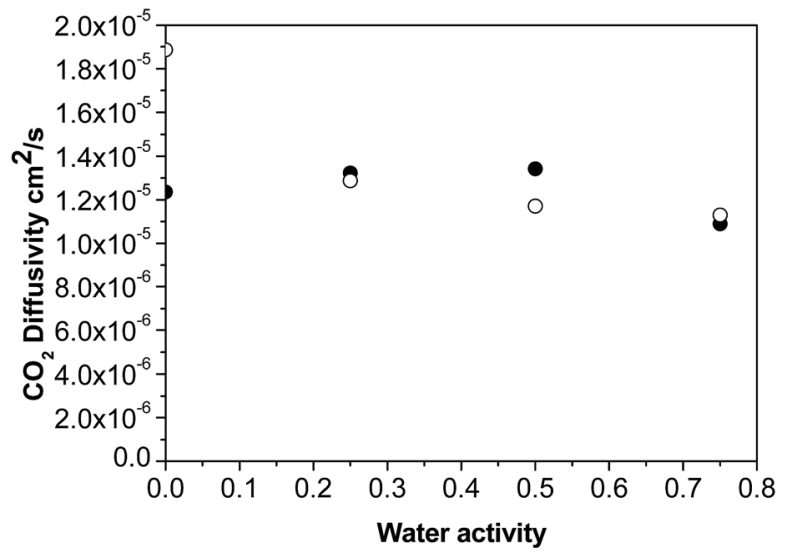

(a)

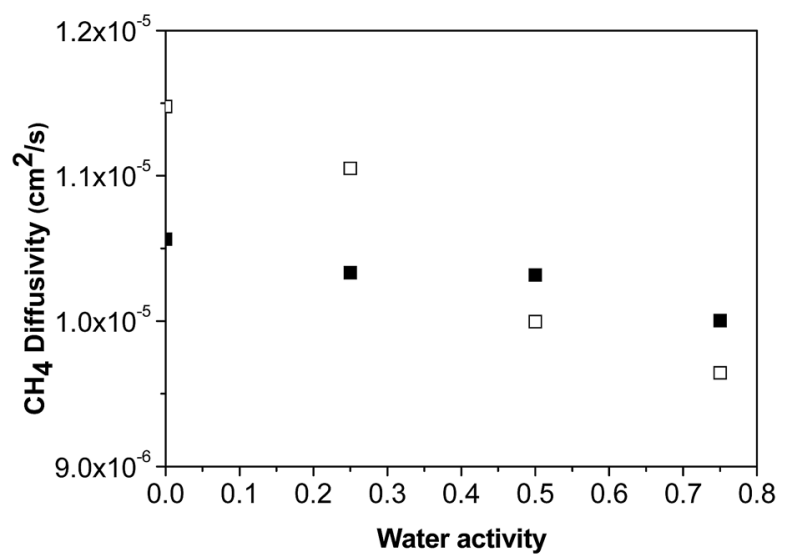

(b)

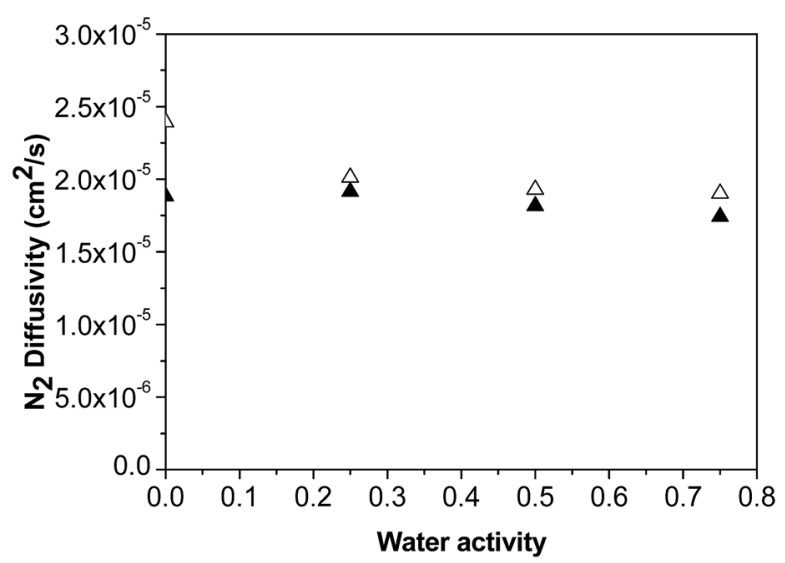

(c)

Fig. 6 Calculated humid gas diffusivity $D(a)$ as a function of water activity of (a) $\mathrm{CO}_{2}$, (b) $\mathrm{CH}_{4}$ and (c) $\mathrm{N}_{2}$, in the PTMSP membrane (void symbols) and the zeolite A/PTMSP MMM (filled symbols).

2.1.3. Comparison of permeability modelling approaches. Once the humid gas diffusivity $D(a)$ and the humid gas solubility $S(a)$ are calculated, the humid gas permeability values obtained by eqn (6) are represented by the dotted lines in Fig. 7 . The humid gas permeability obtained by the simplified model 


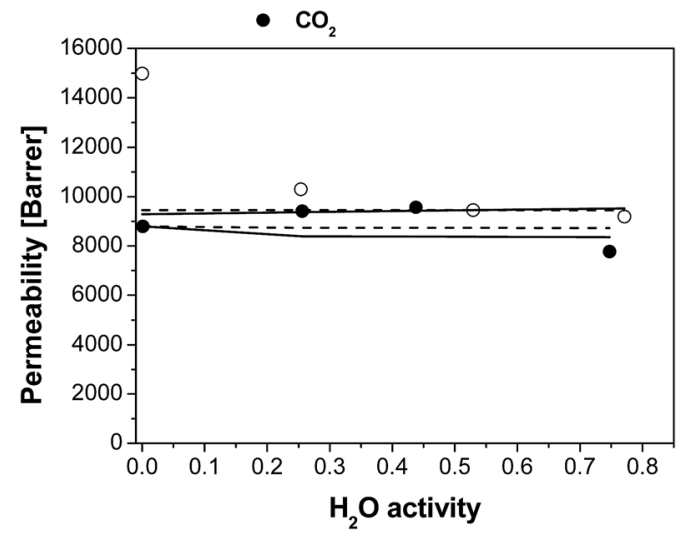

(a)

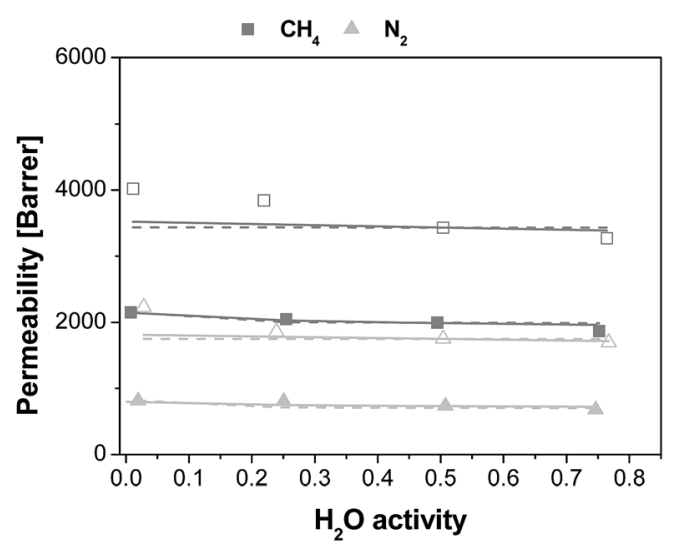

(b)

Fig. 7 Permeability of (a) $\mathrm{CO}_{2}$ (black circles) and (b) $\mathrm{N}_{2}$ (light grey triangles) and $\mathrm{CH}_{4}$ (grey squares) as function of water activity for the PTMSP membrane (void symbols) and the zeolite A/PTMSP MMM (full symbols). Dashed lines correspond to the diffusivity-based model and continuous lines to the (diffusivity + solubility)-based model.

considering only diffusivity (eqn (7)) is plotted as the dashed lines also in Fig. 7, to estimate the contribution of diffusivity and solubility in the prediction of gas permeation through MMM and PTMSP membranes in the presence of relative humidity. There is a good agreement between the experimental results and the predictions of both modelling approaches, and the consideration of water effect on both gas solubility and diffusivity increased the accuracy on the prediction of humid gas permeability. The deviations observed for the pure PTMSP membrane at low water activity were observed by Olivieri et $a l .^{30}$ in the whole range of water activity. We attribute this to the combining effects of competitive sorption and plasticization between gas molecules and the membrane matrix, which may be intensified at increasing relative humidity values.

The adjustable parameters $A$ and $B$ obtained from both approaches are given in Table 5 , as a function of membrane material and gas penetrant. The deviations from the experimental data for both model approaches are also included in Table 5 . The parameter $A$ calculated considering only the effect on humid gas diffusivity on humid gas permeability, by eqn (7), is higher for the PTMSP membrane than the zeolite A/PTMSP MMM, being the highest that of $\mathrm{CO}_{2}$ and the lowest that of $\mathrm{N}_{2}$. This observation is consistent with the order or magnitude of permeability reported by other authors for other polyimide membranes, like Matrimid, ${ }^{29} \mathrm{PSf}^{62}$ or 6 FDA-6FpDA. ${ }^{38}$ When the model equation takes both solubility and diffusivity on the description of humid gas permeability, as in eqn (6), the $A$ parameter of $\mathrm{CH}_{4}$ is lower for the PTMSP membrane than the MMM, while that of $\mathrm{N}_{2}$ is higher for PTMSP than MMM and that of $\mathrm{CO}_{2}$ does not vary. This is also consistent with the experimental behaviour of the humid permeability in the MMM observed in this work. The parameter $B$ predicted by the complete solubility and diffusivity based model is the same in the pristine PTMSP membrane and MMM, for all gases, in agreement with reported data for co-polyetherimides. ${ }^{30}$

It is important to remark that both model approaches employed in this work are able to predict the experimental performance of the PTMSP membrane under humid conditions in a very accurate manner, using only two adjustable parameters depending on the permeating gas and membrane composition. However, the model accounting for solubility and diffusivity estimates better the experimental performance of the MMM. This is attributed to the reduction of free volume by the space occupied by the zeolite particles and the rigidity imparted to the

Table $5 \quad A$ and $B$ adjustable parameters, considering the effects of solubility and diffusivity, eqn (6), and diffusivity only, eqn (7), in the calculation of humid gas permeability

\begin{tabular}{|c|c|c|c|c|}
\hline Modelling approach & Parameter & $\mathrm{N}_{2}$ & $\mathrm{CH}_{4}$ & $\mathrm{CO}_{2}$ \\
\hline \multirow[t]{5}{*}{ Diffusivity model } & \multirow[t]{2}{*}{$A\left(10^{5} \mathrm{~cm}^{2} \mathrm{~s}^{-1}\right)$} & 2.70 (PTMSP) & 3.35 (PTMSP) & 9.05 (PTMSP) \\
\hline & & $2.10(\mathrm{MMM})$ & 3.21 (MMM) & $7.70(\mathrm{MMM})$ \\
\hline & $B(-)$ & $0.319(\mathrm{MMM})$ & $0.165(\mathrm{MMM})$ & 0.015 (MMM) \\
\hline & \multirow[t]{2}{*}{ Error (\%) } & 7.58 (PTMSP) & 7.54 (PTMSP) & 12.70 (PTMSP) \\
\hline & & 4.68 (MMM) & 2.14 (MMM) & 7.38 (MMM) \\
\hline & \multirow[t]{2}{*}{$B(-)$} & 0.040 (PTMSP) & 0.046 (PTMSP) & 0.040 (PTMSP) \\
\hline & & $0.049(\mathrm{MMM})$ & $0.043(\mathrm{MMM})$ & 0.047 (MMM) \\
\hline & \multirow[t]{2}{*}{ Error (\%) } & 6.06 (PTMSP) & 6.45 (PTMSP) & 11.96 (PTMSP) \\
\hline & & 4.03 (MMM) & 1.49 (MMM) & 7.69 (MMM) \\
\hline
\end{tabular}


polymer matrix thereby, ${ }^{19}$ which has a larger effect than plasticization or competitive sorption, ${ }^{\mathbf{4 0}}$ which is accentuated by the presence of the water molecules. As hinted above, this issue requires some research effort in the materials knowledge regarding water sorption and diffusivity, however, it should be remarked that the $\mathrm{CO}_{2}$ solubility of the hydrated zeolite is almost the same as the dried zeolite, in opposition to the solubility of $\mathrm{N}_{2}$ or $\mathrm{CH}_{4}$ (Fig. S2 in the ESI $\dagger$ ).

\section{Experimental}

\subsection{Materials}

Membranes were prepared by the solution casting method as reported elsewhere. ${ }^{19}$ Pure PTMSP membranes were prepared from a $1.5 \mathrm{wt} \%$ toluene solution of PTMSP (ABCR GmbH, Karlsruhe, Germany) and cast on a glass Petri dish. The membranes were then covered by a Petri dish at ambient conditions, to ensure the slow evaporation of the solvent. Before the permeation tests, membranes were immersed in liquid methanol for $5 \mathrm{~min}$, because this was the method that ensured that all the PTMSP-based membranes were in similar initial conditions and presented reproducible permeation performance, ${ }^{19}$ since this is a common procedure for high fractional free volume polymers. ${ }^{63,64}$ The MMM were prepared in a similar way, except that the zeolite particles were previously dispersed in the solvent for $2 \mathrm{~h}$ and added to the polymer solution and stirred for other $24 \mathrm{~h}$ prior to the casting on the glass plate. The nominal zeolite loading in the PTMSP matrix for the MMM studied in this work was $20 \mathrm{wt} \%$, which revealed the highest permselectivity performance in $\mathrm{CO}_{2} / \mathrm{N}_{2}$ separation from a group of PTMSP- based MMM prepared with small-pore zeolites of different $\mathrm{Si} / \mathrm{Al}$ and topology, due to the dual-layer morphology of the zeolite 4A/PTMSP MMM, due to the different densities between zeolite particles and PTMSP and the slow evaporation procedure, which has already been discussed in our previous publications. ${ }^{19,65}$ This MMM consists of a top layer of almost pure PTMSP and a bottom layer containing the zeolite A particles, where the PTMSP acts as a binder, and thanks to the good compatibility between the zeolite $4 \mathrm{~A}$ and the PTMSP, this layer provides thermal and mechanical resistance as well as selectivity to the membrane.

The thickness of the membranes was measured using a digital micrometre (Mitutoyo, precision of $\pm 1 \mu \mathrm{m}$ ). The average thickness of the membranes tested in this work was 60 $\pm 6 \mu \mathrm{m}$.

The membrane density was obtained by the buoyancy method (Sartorius Density Kit YDK01), weighing the samples in air and water.

\subsection{Humid gas permeation experiments}

The effect of the water vapour content on the transport performance of zeolite A/PTMSP MMM and pristine PTMSP membranes has been studied at $35{ }^{\circ} \mathrm{C}$ in the relative humidity (R.H.) range from 0 to $75 \%$. Humid gas permeability tests were carried out in a modified constant volume variable pressure permeometer. The system is equipped with a manometric apparatus that determines the amount of gas diffusing across the membrane by the variation of the gas pressure in a calibrated downstream volume, described in previous works ${ }^{66,67}$ and schematized in Fig. S4 in the ESI. $\uparrow$ There is a humidifying section on the upstream side of the membrane, a water vapour reservoir and a purge flow. After placing the membrane into the sample holder, a vacuum test was performed to ensure the absence of leakage. At the beginning of the experiment, the membrane was equilibrated to the same level of water activity (i.e. the ratio between partial pressure and vapour pressure of water ${ }^{29}$ ) on both sides. When equilibrium was reached, the downstream volume of the apparatus was closed, and the upstream side of the membrane was fed by a gas stream at the same R. H. of the equilibrated membrane. As a consequence, the water activity at both sides of the membrane remained constant along the measurement, so that only the gas species was diffusing across the membrane $\mathrm{e}^{23}$ at each level of R. H.

\subsection{Sorption experiments}

The sorption of $\mathrm{N}_{2}, \mathrm{CH}_{4}$ and $\mathrm{CO}_{2}$ pure gases in the membranes and zeolite powders were measured using a pressure decay equipment reported elsewhere ${ }^{40}$ (drawn in Fig. S5 in the ESI $\dagger$ ) with an average precision of the data higher than 93\%. Before every pure gas sorption experiment, the whole equipment was kept under vacuum overnight. The membrane sample chamber D2 was then isolated from the rest of the equipment by closing valve V1. The volume separated from the surroundings with closed valves V1, V2 and V3 was then pressurized with the penetrant gas. Once the pressure was stable, the experiment was started by opening V1 and waiting several minutes to reach the equilibrium. Then, V1 was closed to set the post-equilibrium pressure. Sequential filling stages were carried out by increasing the pressure stepwise in order to obtain a complete sorption isotherm. The volumes of the membrane sample and pre-chambers, were calibrated by helium expansion experiments using a metal cylinder of known volume as a volume standard. The sorption isotherms were obtained in the order: $\mathrm{N}_{2}, \mathrm{CH}_{4}$ and $\mathrm{CO}_{2}$ at $35{ }^{\circ} \mathrm{C}$. The sorption isotherms for $\mathrm{CH}_{4}$ and $\mathrm{CO}_{2}$ were taken up to 30 bar, while those of $\mathrm{N}_{2}$ only to 10-12 bar, because of the pressure of the $\mathrm{N}_{2}$ bottle. The zeolite samples were measured both as received and dried at $105^{\circ} \mathrm{C}$ for $24 \mathrm{~h}$ in a vacuum oven.

\section{Conclusions}

In this work, the effect of humidity on the gas permeability of $\mathrm{N}_{2}, \mathrm{CH}_{4}$ and $\mathrm{CO}_{2}$ has been studied in the range of relative humidity from $0 \%$ to $75 \%$ at $35{ }^{\circ} \mathrm{C}$ in the new zeolite A/PTMSP MMM whose performance in dry conditions improves that of the pure PTMSP membranes. At a $50 \%$ R. H., while the gas permeability of all the studied gases decreases for pristine PTMSP membranes, the $\mathrm{CO}_{2}$ permeability through the zeolite A/ PTMSP MMM increases up to $10 \%$ from the dry value, and $\mathrm{N}_{2}$ and $\mathrm{CH}_{4}$ permeabilities decrease with water activity.

This behaviour can be related with the reduction of free volume and increased rigidity in the MMM compared to PTMSP 
membranes. Furthermore, it has been proven that the adsorption of $\mathrm{CO}_{2}$ in pure zeolite $\mathrm{A}$ is not impaired by the presence of water, while that of $\mathrm{CH}_{4}$ and of $\mathrm{N}_{2}$ is. Therefore, the presence of zeolite A in PTMSP, under humid conditions, may be generally favourable to the permeation of $\mathrm{CO}_{2}$, while not helping that of $\mathrm{N}_{2}$ or $\mathrm{CH}_{4}$. Thus, the selectivity of zeolite A/PTMSP MMM is enhanced with increasing relative humidity in the feed in all the water activity range studied.

The sorption of gases in PTMSP and MMM has been measured experimentally and adjusted accurately by the NELF model, for all gases considered, using an approach for composite structures.

The permeability of gases in humid conditions in both pure PTMSP membranes and MMM is also modelled with a tool based on the free volume theory for diffusion, and NELF for sorption, with only two adjustable parameters. While the diffusivity only -based model equation predicts accurately the humid gas permeability through pristine PTMSP glassy polyimide membranes, the consideration of both solubility and diffusivity is necessary to approach the experimental results obtained in the laboratory for the novel zeolite A/PTMSP MMM under humid conditions in a very accurate way. This gives scope to the relevance of considering the multicomponent competitive sorption and the free volume reduction by occupation of the hydrophobic polymer matrix by water molecules and the hydrophilic character of zeolite fillers in the model prediction of new membranes with potential application in the treatment of humid gas streams.

\section{Conflicts of interest}

There are no conflicts to declare.

\section{Acknowledgements}

Financial support is gratefully acknowledged to the Spanish Ministry of Economy and Competitiveness (MINECO) under projects CTQ2016-76231-C2-1-R and CTQ2012-31229 at the University of Cantabria. A. F. B. also thanks the MINECO for the Early Stage Researcher (BES2013-064266) contract and the short stay grant to work at the University of Bologna for 3 months (EEBB-I-17-12097).

\section{References}

1 R. S. Haszeldine, Science, 2009, 325, 1647-1652.

2 J. C. Abanades, B. Arias, A. Lyngfelt, T. Mattisson, D. E. Wiley, H. Li, M. T. Ho, E. Mangano and S. Brandani, Int. J. Greenhouse Gas Control, 2015, 40, 126-166.

3 E. S. Rubin, H. Mantripragada, A. Marks, P. Versteeg and J. Kitchin, Prog. Energy Combust. Sci., 2012, 38, 630-671.

4 P. Luis, T. Van Gerven and B. Van der Bruggen, Prog. Energy Combust. Sci., 2012, 38, 419-448.

5 R. Khalilpour, K. Mumford, H. Zhai, A. Abbas, G. Stevens and E. S. Rubin, J. Cleaner Prod., 2015, 103, 286-300.

6 L. Giordano, D. Roizard, R. Bounaceur and E. Favre, Energy, 2016, 116, 517-525.
7 K. Ramasubramanian, Y. Zhao and W. S. Winston Ho, AIChE J., 2013, 59, 1033-1045.

8 S. Wang, X. Li, H. Wu, Z. Tian, Q. Xin, G. He, D. Peng, S. Chen, Y. Yin, Z. Jiang, M. D. Guiver, S. Wang, X. Li, H. Wu, Z. Tian, Q. Xin, G. He, D. Peng, S. Chen, Y. Yin, Z. Jiang and M. D. Guiver, Energy Environ. Sci., 2016, 9, 1863-1890.

9 L. M. Robeson, J. Membr. Sci., 2008, 320, 390-400.

10 S. Roussanaly, R. Anantharaman, K. Lindqvist, H. Zhai and E. Rubin, J. Membr. Sci., 2016, 511, 250-264.

11 M. Rezakazemi, A. Ebadi Amooghin, M. M. MontazerRahmati, A. F. Ismail and T. Matsuura, Prog. Polym. Sci., 2014, 39, 817-861.

12 D. Bastani, N. Esmaeili and M. Asadollahi, J. Ind. Eng. Chem., 2013, 19, 375-393.

13 N. Jusoh, Y. Fong Yeong, T. Leng Chew, K. Keong Lau and A. Mohd Shariff, Sep. Purif. Technol., 2016, 454, 321-344.

14 A. Morisato, H. C. Shen, S. S. Sankar, B. D. Freeman, I. Pinnau and C. G. Casillas, J. Polym. Sci., Part B: Polym. Phys., 1996, 34, 2209-2222.

15 K. Nagai, T. Masuda, T. Nakagawa, B. D. Freeman and I. Pinnau, Prog. Polym. Sci., 2001, 26, 721-798.

16 T. C. Merkel, R. P. Gupta, B. S. Turk and B. D. Freeman, J. Membr. Sci., 2001, 191, 85-94.

17 X. Y. Wang, A. J. Hill, B. D. Freeman and I. C. Sanchez, J. Membr. Sci., 2008, 314, 15-23.

18 S. D. Kelman, B. W. Rowe, C. W. Bielawski, S. J. Pas, A. J. Hill, D. R. Paul and B. D. Freeman, J. Membr. Sci., 2008, 320, 123134.

19 A. Fernández-Barquín, C. Casado-Coterillo, M. Palomino, S. Valencia and A. Irabien, Chem. Eng. Technol., 2015, 38, 658-666.

20 L. Ansaloni, J. R. Nykaza, Y. Ye, Y. A. Elabd and M. Giacinti Baschetti, J. Membr. Sci., 2015, 487, 199-208.

21 C. A. Scholes, J. Jin, G. W. Stevens and S. E. Kentish, J. Polym. Sci., Part B: Polym. Phys., 2015, 53, 719-728.

22 G. Q. Chen, S. Kanehashi, C. M. Doherty, A. J. Hill and S. E. Kentish, J. Membr. Sci., 2015, 487, 249-255.

23 M. Giacinti Baschetti, M. Minelli, J. Catalano and G. C. Sarti, Int. J. Hydrogen Energy, 2013, 38, 11973-11982.

24 T. Mizumoto, T. Masuda and T. Higashimura, J. Polym. Sci., Part A: Polym. Chem., 1993, 31, 255-2561.

25 W. Yave, K.-V. Peinemann, S. Shishatskiy, V. Khotimskiy, M. Chirkova, S. Matson, E. Litvinova and N. Lecerf, Macromolecules, 2007, 40, 8991-8998.

26 C. A. Scholes, B. D. Freeman and S. E. Kentish, J. Membr. Sci., 2014, 470, 132-137.

27 J. H. Lee, J. Lee, H. J. Jo, J. G. Seong, J. S. Kim, W. H. Lee, J. Moon, D. Lee, W. J. Oh, J. gu Yeo and Y. M. Lee, J. Membr. Sci., 2017, 539, 412-420.

28 K. Nakamura, T. Kitagawa, S. Nara, T. Wakamatsu, Y. Ishiba, S. Kanehashi, S. Sato and K. Nagai, Ind. Eng. Chem. Res., 2013, 52, 1133-1140.

29 L. Ansaloni, M. Minelli, M. Giacinti Baschetti and G. C. Sarti, J. Membr. Sci., 2014, 471, 392-401. 
30 L. Olivieri, A. Tena, M. G. De Angelis, A. Hernández Giménez, A. E. Lozano and G. C. Sarti, Green Energy Environment, 2016, 1, 201-210.

31 S. J. D. Smith, H. Lau, J. I. Mardel, M. Kitchin, K. Konstas, P. Ladewig and M. R. Hill, J. Mater. Chem. A, 2016, 4, 10627-10634.

32 E. Lasseuguette, M. Carta, S. Brandani and M. C. Ferrari, Int. J. Greenhouse Gas Control, 2016, 50, 93-99.

33 T. T. Moore and W. J. Koros, J. Appl. Polym. Sci., 2007, 104, 4053-4059.

34 R. Y. Yanagida, A. A. Amaro and K. Seff, J. Phys. Chem., 1973, 77, 805-809.

35 X. Ren, K. Nishimoto, M. Kanezashi, H. Nagasawa, T. Yoshioka and T. Tsuru, Ind. Eng. Chem. Res., 2014, 53, 6113-6120.

36 M. Palomino, A. Corma, F. Rey and S. Valencia, Langmuir, 2010, 26, 1910-1917.

37 B. Ozturk and F. Demirciyeva, Chem. Eng. J., 2013, 222, 209217.

38 C. Tsvigu, E. Pavesi, M. G. G. De Angelis and M. Giacinti Baschetti, J. Membr. Sci., 2015, 485, 60-68.

39 H. Azher, C. Scholes, S. Kanehashi, G. Stevens and S. Kentish, J. Membr. Sci., 2016, 519, 55-63.

40 O. Vopička, M. G. De Angelis and G. C. Sarti, J. Membr. Sci., 2014, 449, 97-108.

41 M. Minelli and G. C. Sarti, J. Membr. Sci., 2013, 435, 176-185. 42 M. Minelli and G. C. Sarti, Fluid Phase Equilib., 2016, 424, 4451.

43 M. Minelli and G. C. Sarti, J. Membr. Sci., 2017, 521, 73-83. 44 M. G. De Angelis and G. C. Sarti, Annu. Rev. Chem. Biomol. Eng., 2011, 2, 97-120.

45 K. Nagai, S. Kanehashi, S. Tabei and T. Nakagawa, J. Membr. Sci., 2005, 251, 101-110.

46 M. G. De Angelis and G. C. Sarti, Ind. Eng. Chem. Res., 2008, 47, 5214-5226.

47 M. Minelli, G. Coochi, L. Ansaloni, M. Giacinti Baschetti, M. G. De Angelis and F. Doghieri, Ind. Eng. Chem. Res., 2013, 52, 8936-8945.

48 M. Galizia, K. A. Stevens, Z. P. Smith, D. R. Paul and B. D. Freeman, Macromolecules, 2016, 49, 8768-8779.
49 M. C. Ferrari, M. Galizia, M. G. De Angelis and G. C. Sarti, Ind. Eng. Chem. Res., 2010, 49, 11920-11935.

50 A. J. Hill, B. D. Freeman, M. Jaffe, T. C. Merkel and I. Pinnau, J. Mol. Struct., 2005, 739, 173-178.

51 M. Galizia, M. G. De Angelis, M. Messori and G. C. Sarti, Ind. Eng. Chem. Res., 2014, 53, 9243-9255.

52 M. C. Ferrari, M. Galizia, M. G. De Angelis and G. C. Sarti, Ind. Eng. Chem. Res., 2010, 49, 11920-11935.

53 M. Woo, J. Choi and M. Tsapatsis, Microporous Mesoporous Mater., 2008, 110, 330-338.

54 A. L. Ahmad, J. K. Adewole, C. P. Leo, S. Ismail, A. S. Sultan and S. O. Olatunji, J. Membr. Sci., 2015, 480, 39-46.

55 J. Park and D. R. Paul, J. Membr. Sci., 1997, 125, 23-39.

56 J. S. S. Vrentas, J. L. L. Duda and H. C. C. Ling, J. Membr. Sci., 1989, 40, 101-107.

57 Y. Huang, X. Wang and D. R. Paul, J. Membr. Sci., 2006, 277, 219-229.

58 G. Consolati, I. Genco, M. Pegoraro and L. Zanderighi, J. Polym. Sci., Part B: Polym. Phys., 1996, 34, 357-367.

59 A. Bondi, J. Phys. Chem., 1964, 68, 441-451.

60 K. Okamoto, H. Kita and K. Horii, Ind. Eng. Chem. Res., 2001, 40, 163-175.

61 R. H. Perry, D. W. Green and J. O. Maloney, Perry's Chemical Engineer's Handbook, McGraw-Hill Professional, 8th edn, 2007, vol. 27.

62 B. W. Rowe, B. D. Freeman and D. R. Paul, Polymer (Guildf), 2009, 50, 5565-5575.

63 S. D. Kelman, S. Matteucci, C. W. Bielawski and B. D. Freeman, Polymer (Guildf), 2007, 48, 6881-6892.

64 A. J. Hill, S. J. Pas, T. J. Bastow, M. I. Burgar, K. Nagai, L. G. Toy and B. D. Freeman, J. Membr. Sci., 2004, 243, 37-44.

65 A. Fernández-Barquín, C. Casado-Coterillo, M. Palomino, S. Valencia and A. Irabien, Sep. Purif. Technol., 2016, 157, 102-111.

66 M. Minelli, M. G. Baschetti, F. Doghieri, M. Ankerfors, T. Lindström, I. Siró and D. Plackett, J. Membr. Sci., 2010, 358, 67-75.

67 J. Catalano, T. Myezwa, M. G. De Angelis, M. G. Baschetti and G. C. Sarti, Int. J. Hydrogen Energy, 2012, 37, 6308-6316. 